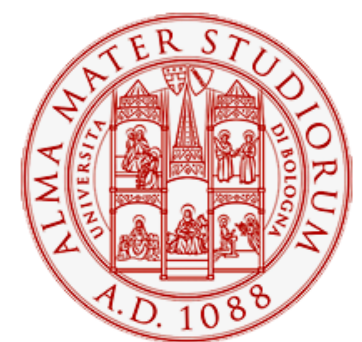

Alma Mater Studiorum - Università di Bologna DEPARTMENT OF ECONOMICS

Low-Quality Leadership in a Vertically

Differentiated Duopoly with Cournot

Competition

Luca Lambertini

Alessandro Tampieri

Quaderni - Working Paper DSE N 750

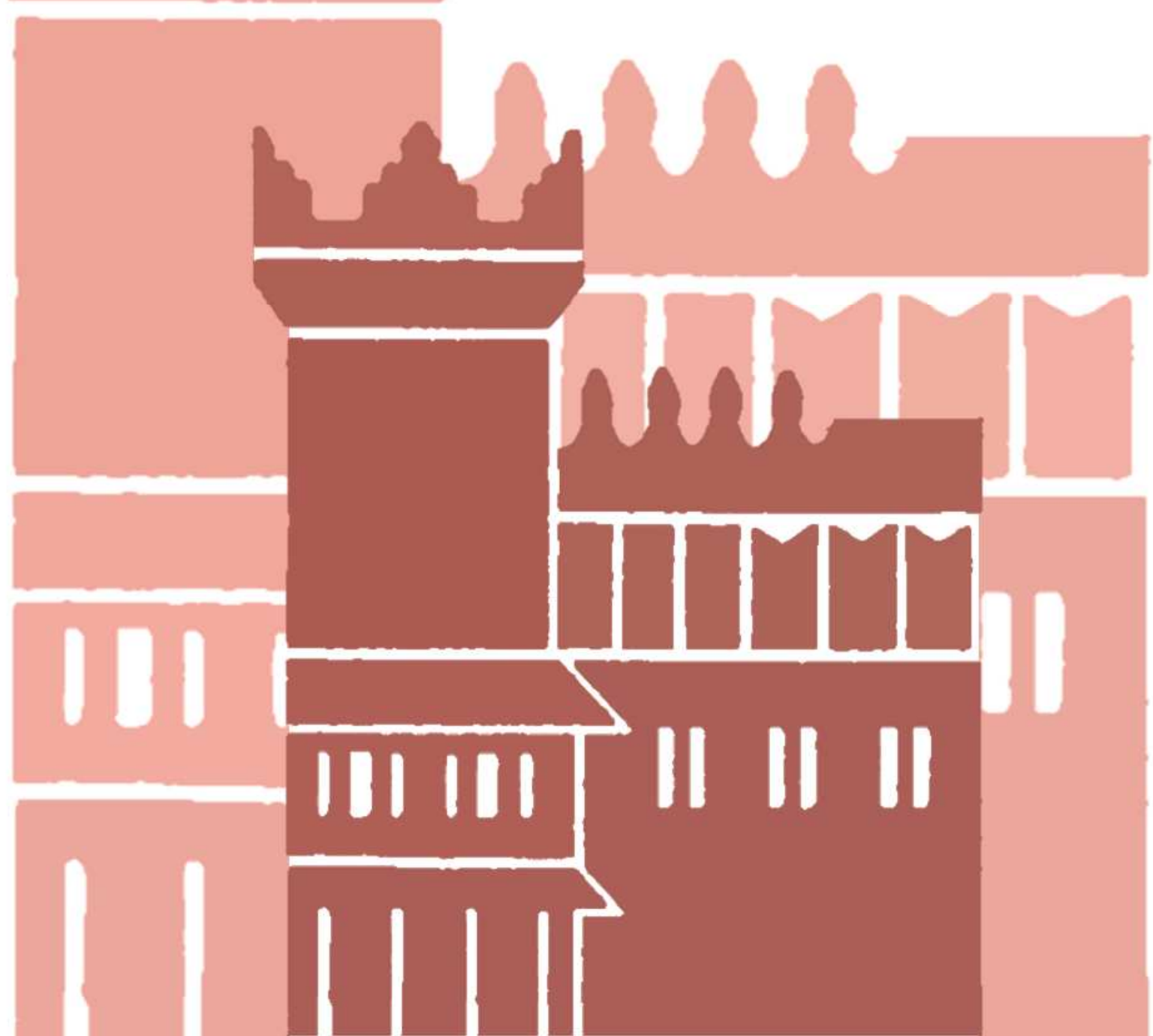




\title{
Low-Quality Leadership in a Vertically Differentiated Duopoly with Cournot Competition
}

\author{
Luca Lambertini ${ }^{\S, \#}$ and Alessandro Tampieri ${ }^{\S}$ \\ $\S$ Department of Economics, University of Bologna \\ Strada Maggiore 45, 40125 Bologna, Italy \\ luca.lambertini@unibo.it; alessandro.tampieri@unibo.it \\ \# ENCORE, University of Amsterdam \\ Roetersstraat 11, WB1018 Amsterdam, The Netherlands
}

May 20, 2011

\begin{abstract}
We model a vertically differentiated duopoly with quantity-setting firms as an extended game in which firms noncooperatively choose the timing of moves at the quality stage, to show that at the subgame perfect equilibrium sequential play obtains, with the low-quality firm taking the leader's role.
\end{abstract}

JEL codes: C73, L13

Keywords: endogenous timing, product quality 


\section{Introduction}

A well established result produced by the theory of vertical differentiation is that the first entrant fills the highest quality niche, letting newcomers locate further down along the quality spectrum. This result is commonly derived under Bertrand competition (see Gabszewicz and Thisse, 1979; Shaked and Sutton, 1982; Aoki and Prusa, 1997; and Lehmann-Grube, 1997, inter alia). The opposite may apply if the role of time is accounted for, in such a way that low-quality leadership emerges when the exploitation of ad interim monopoly power matters more than skinning the cream (see van Dijk, 1996; and Lambertini and Tedeschi, 2007a,b).

Here we take a different angle to address the same issue, exploiting an idea dating back to d'Aspremont and Gérard-Varet (1980) and then further developed by Hamilton and Slutsky (1990), according to whom a game is Stackelberg-solvable if there exists a Stackelberg equilibrium that Paretodominates the Nash solution. We use this approach in a vertically differentiated duopoly in which firms bear a convex cost of quality improvement and then behave à la Cournot-Nash. From the analysis of the quality stage, there emerges that, while the high-quality firm's best reply is increasing, that of the low-quality firm is decreasing, and therefore the choice of roles concerning the timing of moves in the quality space univocally selects sequential play with low-quality leadership as part of the subgame perfect equilibrium. This framework may indeed fit real-world episodes in which innovation from below has been observed; one such instance is the introduction of solid state (transistor) circuitry to replace vacuum tube designs in consumer electronics at the turn of the Seventies, with a large production characterised by a comparatively lower quality, higher quality versions being introduced later. 


\section{The model}

We consider a duopoly market for vertically differentiated products supplied by single-product firms. The demand side is modelled à la Mussa and Rosen (1978). There is a continuum of consumers whose types are identified by $\theta$, uniformly distributed with density equal to one in the interval $[0, \Theta]$ (so that total demand is equal to $\Theta$ ). Parameter $\theta$ represents the consumers' marginal willingness to pay for quality. Each consumer is assumed to buy at most one unit of the vertically differentiated good in order to maximise the following surplus function:

$$
U=\theta q_{i}-p_{i}
$$

where $q_{i} \in[0, Q]$ indicates the quality of the product and $p_{i}$ is the market price at which that variety is supplied by firm $i=H, L$, with $q_{H} \geq q_{L}$. Therefore, the consumer who is indifferent between $q_{H}$ and $q_{L}$ is identified by the level of marginal willingness to pay $\widehat{\theta}$ that solves $\widehat{\theta} q_{H}-p_{H}=\widehat{\theta} q_{L}-p_{L}$, and therefore $\widehat{\theta}=\left(p_{H}-p_{L}\right) /\left(q_{H}-q_{L}\right)$. Thus, market demand for the highquality good is $x_{H}=\Theta-\widehat{\theta}$. We assume partial market coverage, so that there exists a consumer indifferent between buying $q_{L}$ or not buying at all, identified by $\widetilde{\theta}$ solving $\widetilde{\theta} q_{L}-p_{L}=0$, whereby $\widetilde{\theta}=p_{L} / q_{L}$ and the demand for the inferior variety is $x_{L}=\widehat{\theta}-\widetilde{\theta}$. This is what one needs to use in order to model Bertrand behaviour, while inverse demands

$$
\begin{gathered}
p_{H}=\left(\Theta-x_{H}\right) q_{H}-q_{L} x_{L} \\
p_{L}=\left(\Theta-x_{H}-x_{L}\right) q_{L}
\end{gathered}
$$

are to be used under Cournot competition.

On the supply side, as in Motta (1993), inter alia, firms incur in convex fixed costs of quality improvement $C_{i}=c q_{i}^{2}, i=H, L$. Variable costs are assumed away. Hence profit functions are $\pi_{H}=p_{H} x_{H}-c q_{H}^{2}$ and $\pi_{L}=$ $p_{L} x_{L}-c q_{L}^{2}$. Competition takes place in three stages. In the first, firms choose the timing to be followed in the second stage, where qualities are set, and 
then in the third stage simultaneous Cournot competition takes place. The solution concept is the subgame perfect equilibrium by backward induction.

The first stage is a pre-play stage à la Hamilton and Slutsky (1990), in which, under complete, symmetric and imperfect information, firms play a discrete strategy game represented in Matrix 1.

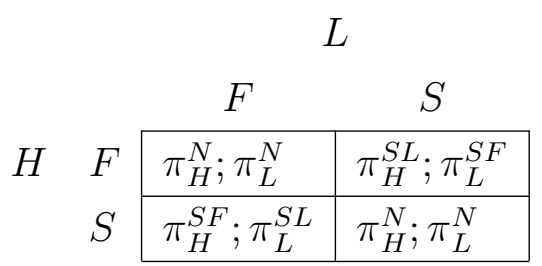

Matrix 1

Actions $F$ and $S$ stand for "first" or "second", and refers to the choice of roles pertaining to the quality stage, while superscripts $N, S L$, and $S F$ stand for Nash, Stackelberg leader and Stackelberg follower, respectively. If firms select the same strategy - along the main diagonal - then the second-stage quality game is simultaneous. Conversely, along the secondary diagonal, the quality stage is going to be solved à la Stackelberg. For future reference, it is worth recalling that the firms' incentives as to the timing of moves is entirely driven by the slope of their best replies (in this case, in the quality space), in such a way that if a firm has a decreasing (resp., increasing) reaction function, it will prefer to move first (resp., second) (see Hamilton and Slutsky, 1990, Theorem V, p. 38).

\section{Results}

To begin with, we characterise optimal outputs for any given quality pair:

$$
x_{H}^{N}=\frac{\Theta\left(2 q_{H}-q_{L}\right)}{4 q_{H}-q_{L}} ; x_{L}^{N}=\frac{\Theta q_{H}}{4 q_{H}-q_{L}}
$$


where superscript $N$ stands for Nash equilibrium. The explicit derivation of the Cournot equilibrium is omitted as it is known from Motta (1993).

We now turn to the second stage where the quality game takes place. The relevant profit functions are:

$$
\begin{gathered}
\pi_{H}=\frac{q_{H}\left[\Theta^{2}\left(2 q_{H}-q_{L}\right)^{2}-c q_{H}\left(4 q_{H}-q_{L}\right)^{2}\right]}{\left(4 q_{H}-q_{L}\right)^{2}} \\
\pi_{L}=\frac{q_{L}\left[\Theta^{2} q_{H}^{2}-c q_{L}\left(4 q_{H}-q_{L}\right)^{2}\right]}{\left(4 q_{H}-q_{L}\right)^{2}}
\end{gathered}
$$

The first order conditions for non cooperative profit maximisation are:

$$
\begin{gathered}
\frac{\partial \pi_{H}}{\partial q_{H}}=\frac{\Theta^{2}\left(16 q_{H}^{3}-12 q_{H}^{2} q_{L}+4 q_{H} q_{L}^{2}-q_{L}^{3}\right)-2 c q_{H}\left(4 q_{H}-q_{L}\right)^{3}}{\left(4 q_{H}-q_{L}\right)^{3}}=0, \\
\frac{\partial \pi_{L}}{\partial q_{L}}=\frac{\Theta^{2} q_{H}^{2}\left(4 q_{H}+q_{L}\right)-2 c\left(4 q_{H}-q_{L}\right)^{3}}{\left(4 q_{H}-q_{L}\right)^{3}}=0 .
\end{gathered}
$$

Given that the above FOCs do not allow for a fully analytical characterisation of Nash and Stackelberg equilibria, we investigate the solution of the quality stage by studying the map of the reaction functions, implicitly revealed by (5-6). In particular, following Bulow et al. (1985), we know that the nature of strategic interaction is entirely determined by the sign of the partial derivatives of FOCs with respect to the competitor's quality, which ultimately indicate the slopes of reaction functions $q_{i}^{*}\left(q_{j}\right), i, j=H, L, i \neq j$. These derivatives are:

$$
\begin{gathered}
\frac{\partial q_{H}^{*}\left(q_{L}\right)}{\partial q_{L}} \propto \frac{\partial^{2} \pi_{H}}{\partial q_{H} \partial q_{L}}=\frac{8 \Theta^{2} q_{H} q_{L}\left(q_{H}-q_{L}\right)}{\left(4 q_{H}-q_{L}\right)^{4}}>0, \\
\frac{\partial q_{L}^{*}\left(q_{H}\right)}{\partial q_{H}} \propto \frac{\partial^{2} \pi_{L}}{\partial q_{L} \partial q_{H}}=-\frac{2 \Theta^{2} q_{H} q_{L}\left(8 q_{H}+q_{L}\right)}{\left(4 q_{H}-q_{L}\right)^{4}}<0 .
\end{gathered}
$$

The concavity/convexity of best replies is determined by the following derivatives:

$$
\frac{\partial^{3} \pi_{H}}{\partial q_{H} \partial q_{L}^{2}}=-\frac{8 \Theta^{2}\left(4 q_{H}^{2}-5 q_{H} q_{L}-2 q_{L}^{2}\right)}{\left(4 q_{H}-q_{L}\right)^{5}},
$$


which is positive for all $q_{H} \in\left(0, \frac{5+\sqrt{57}}{8} q_{L}\right)$ and negative for all $q_{H}>$ $\frac{5+\sqrt{57}}{8} q_{L} ;$ and

$$
\frac{\partial^{3} \pi_{L}}{\partial q_{L} \partial q_{H}^{2}}=\frac{2 \Theta^{2} q_{L}\left(64 q_{H}^{2}+28 q_{H} q_{L}+q_{L}^{2}\right)}{\left(4 q_{H}-q_{L}\right)^{5}}>0
$$

Hence $q_{H}^{*}\left(q_{L}\right)$ is always increasing and convex for all $q_{H} \in\left(0, \frac{5+\sqrt{57}}{8} q_{L}\right)$ and concave for all $q_{H}>\frac{5+\sqrt{57}}{8} q_{L}$. On the other hand, $q_{L}^{*}\left(q_{H}\right)$ is everywhere decreasing and convex.

A Nash equilibium exists if the vertical intercept of $q_{H}^{*}\left(q_{L}\right)$ is lower than the vertical intercept of $q_{L}^{*}\left(q_{H}\right)$ in the space $\left\{q_{L}, q_{H}\right\}$. We can see that:

$$
\left.\frac{\partial \pi_{H}}{\partial q_{H}}\right|_{q_{L}=0}=-\frac{\Theta^{2}-8 c q_{H}}{4}=0
$$

so that $\left.q_{H}^{*}\left(q_{L}\right)\right|_{q_{L}=0}=\Theta^{2} /(8 c)$, while there are no solutions w.r.t. $q_{H}$ to $\partial \pi_{L} /\left.\partial q_{L}\right|_{q_{L}=0}=0$. Therefore, defining $\widehat{q}_{H} \equiv\left(q_{L}^{*}\left(q_{H}\right)\right)^{-1}$, we have $\lim _{q_{L} \rightarrow 0} \widehat{q}_{H}=$ $+\infty$.

Figure 1 shows the map of the best replies and the respective isoprofit curves. The Nash equilibrium (point $N$ ) yields a lower profit both to firm $L$ and to firm $H$ as compared to the Stackelberg equilibrium where $L$ acts as the leader (point $S_{L}$ ). As to the Stackelberg solution with firm $H$ leading, the map of isoprofit curves reveals that the high-quality firm is better off w.r.t. the Nash equilibrium, while the opposite applies to the low-quality firm. Overall, the following chains of inequalities hold:

$$
\begin{aligned}
& \pi_{H}^{S F}>\pi_{H}^{S L}>\pi_{H}^{N} \\
& \pi_{L}^{S L}>\pi_{L}^{N}>\pi_{L}^{S F}
\end{aligned}
$$


Figure 1. The map of best replies with the equilibrium points.

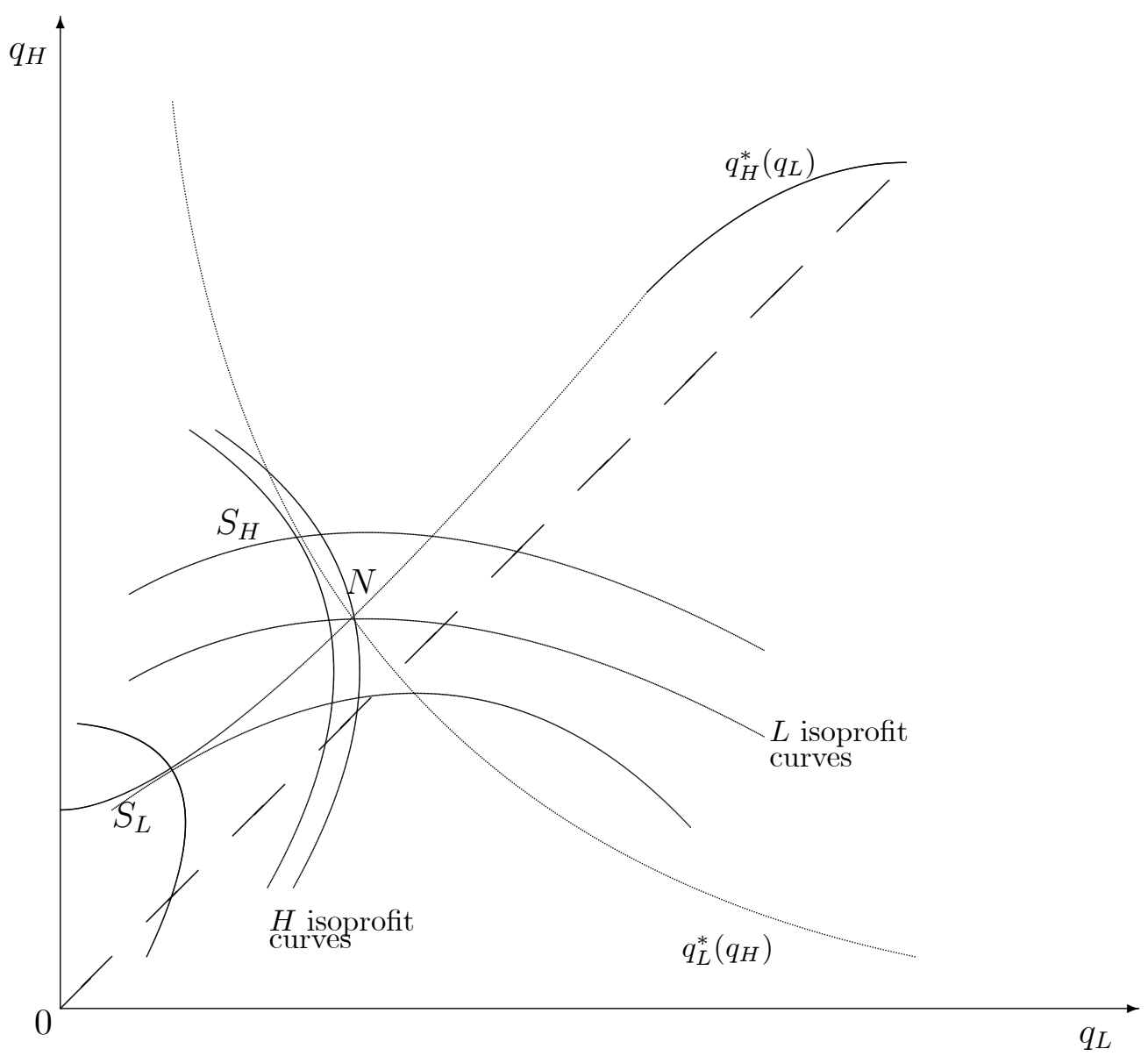

Using these properties, one can go back to Matrix 1 and observe that the first (pre-play) stage can be solved by applying iterated dominance, since (i) firm $L$ drops strategy $S$ as it is strictly dominated by $F$; then, (ii) firm $H$ drops what remains of strategy $F$, and therefore (iii) the matrix reduces to the cell $(S, F)$. This discussion allows us to formulate

Proposition 1 The three-stage game has a unique subgame perfect equilibrium in pure strategies, where firm L takes the lead in the quality stage. 
To this regard, it is worth remarking that the slopes of reaction functions and the ranking of payoffs in (12) are the two sides of the same coin, the first dating back to Hamilton and Slutsky (1990), the second to d'Aspremont and Gérard-Varet (1980). Taken together, these two features of the second stage of the game allow players to select the timing of moves so as to attain at equilibrium the Pareto-efficient outcome.

As a last remark, observe that, as switching from simultaneous to sequantial play with firm $L$ leading involves a decrease in both quality levels. This surely has negative consequences on consumer surplus

$$
C S=\int_{\widetilde{\theta}}^{\widehat{\theta}}\left(k q_{L}-p_{L}\right) d k+\int_{\widehat{\theta}}^{\Theta}\left(z q_{H}-p_{H}\right) d z
$$

as can be ascertained from the following partial derivatives:

$$
\frac{\partial C S}{\partial q_{H}}=\frac{\Theta^{2}\left[4 q_{H}^{2}\left(4 q_{H}-3 q_{L}\right)+q_{L}^{2}\left(2 q_{H}+q_{L}\right)\right]}{2\left(4 q_{H}-q_{L}\right)^{3}} ; \frac{\partial C S}{\partial q_{L}}=\frac{\Theta^{2} q_{H}^{2}\left(12 q_{H}-7 q_{L}\right)}{2\left(4 q_{H}-q_{L}\right)^{3}}
$$

which are both positive. Hence, the balance between the increase in industry profits and the decrease in consumer surplus is ambigous.

\section{References}

[1] Aoki, R., and Prusa, T. (1997). Sequential versus Simultaneous Choice with Endogenous Quality. International Journal of Industrial Organization 15: 103-121.

[2] Bulow, J., Geanakoplos, J. and Klemperer, P. (1985). Multimarket Oligopoly: Strategic Substitutes and Complements. Journal of Political Economy 93: 488-511.

[3] d'Aspremont, C. and Gérard-Varet, L.-A. (1980). Stackelberg-Solvable Games and Pre-Play Communication. Journal of Economic Theory 23: 201-217. 
[4] Gabszewicz, J.J. and Thisse, J.-F. (1979). Price Competition, Quality, and Income Disparity. Journal of Economic Theory 20: 340-359.

[5] Lambertini, L. and Tedeschi, P. (2007a). Would You Like to Enter First with a Low-Quality Good? Bulletin of Economic Research 59: 269-282.

[6] Lambertini, L. and Tedeschi, P. (2007b). On the Social Desirability of Patents for Sequential Innovations in a Vertically Differentiated Market. Journal of Economics 90: 193-214.

[7] Lehmann-Grube, U. (1997). Strategic Choice of Quality when Quality Is Costly: The Persistence of the High-Quality Advantage. RAND Journal of Economics 28: 372-384.

[8] Motta, M. (1993). Endogenous Quality Choice: Price vs. Quantity Competition. Journal of Industrial Economics 41: 113-131.

[9] Hamilton, J. and Slutsky, S. (1990). Endogenous Timing in Duopoly Games: Stackelberg or Cournot Equilibria. Games and Economic Behavior 2: 29-46.

[10] Mussa, M. and Rosen, S. (1978). Monopoly and Product Quality. Journal of Economic Theory 18: 301-317.

[11] Shaked, A. and Sutton, J. (1982). Relaxing Price Competition through Product Differentiation. Review of Economic Studies 49: 3-13.

[12] van Dijk, T. (1996). Patent Height and Competition in Product Improvements. Journal of Industrial Economics 44: 151-167. 


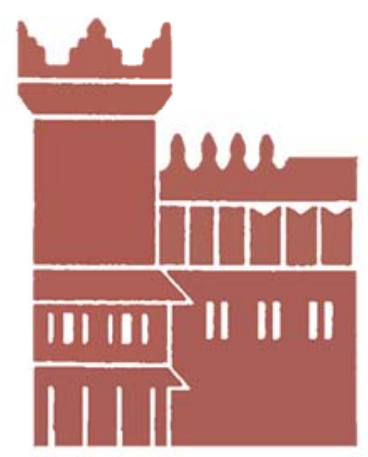

Alma Mater Studiorum - Università di Bologna DEPARTMENT OF ECONOMICS

Strada Maggiore 45

40125 Bologna - Italy

Tel. +39051 2092604

Fax +390512092664

http://www.dse.unibo.it 